\title{
LIDAR IN EXTREME ENVIRONMENT: SURVEYING IN ANTARCTICA
}

\author{
D. Abate ${ }^{\text {a }}$, S. Pierattini ${ }^{\text {a }}$, G. Bianchi Fasani ${ }^{\text {b }}$ \\ ${ }^{\text {a }}$ Technical Unit for ICT, ENEA Research Centre, Bologna, Italy \\ dante.abate@enea.it, samuele.pierattini@enea.it \\ b Technical Unit for Antarctica, ENEA Research Centre, Casaccia (RM), Italy \\ gianluca.bianchifasani@enea.it
}

\section{Commission VI, WG VI/4}

KEY WORDS: Laser Scanning, Antarctica, Extreme Environment, 3D Modelling, Landscape

\begin{abstract}
:
This study was performed under the patronage of the Italian National Research Programme in Antarctica (PNRA) with the aim to realize a high resolution Digital Elevation Model (DEM) of the moraine named "Boulder Clay" which insists approximately $7 \mathrm{~km}$ far from the Italian Research Base "Mario Zucchelli Station" in the Terra Nova Bay area. The DEM will be included in the project for the construction of two runways to be used as support facilities for the scientific research campaigns which take place on regular basis each year.

Although the research efforts to realize a detailed cartography of the area is on-going, for the specific aim and urgency of this project it was decided to perform a laser scanning survey in this extreme environment in order to obtain contour lines describing the terrain elevation each $50 \mathrm{~cm}$ and volume analysis.

The final result will be super imposed on a photogrammetric DEM with contour lines each $2.5 \mathrm{~m}$ and satellite images.

This paper focus both on the final scientific data and on all the challenges have to be faced in such extreme and particular environment during the laser scanning survey.
\end{abstract}

\section{INTRODUCTION}

\subsection{Logistic in Antarctica}

For the transport of personnel, scientific instruments and materials necessary for the logistics, the scientific expeditions in Antarctica typically use cargo flights which, in optimal conditions, land on airstrips realized on the sea ice shelf which forms along the coast during the winter season.

Even the Italian expedition uses similar structures. The runway for cargo transport Hercules C-130 aircraft is commonly prepared on the pack area called Gerlache Inlet and Thetys Bay (Figure 1).

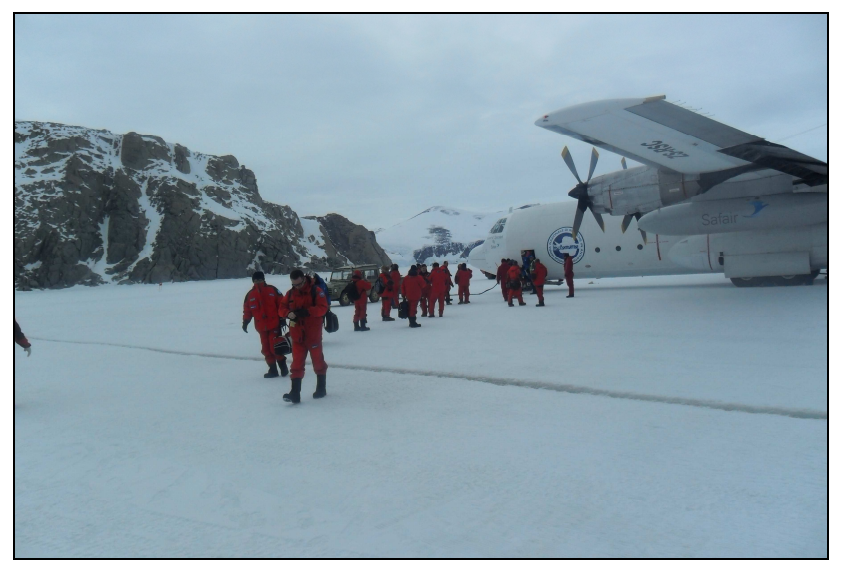

However in the past few years it has been observed that the Campbell glacier, which is located near Terra Nova Bay, East Antarctica, is retreating. The glacier's tongue is not indeed protecting anymore the Thetys bay and the high speed katabatic wind, which blows from the surrounding mountains, often breaks apart the ice sheet formed during the austral winter. This means that the sea ice sheet since few years is getting less thick at the beginning of the summer season thus decreasing the chances to use the airstrip (PNRA, 2005; PNRA, 2008; PNRA, 2009; PNRA, 2010; Bromwich, 2012).

It has been decided then to design two runways on land, available during all seasons. A high resolution DEM is necessary to draft of the preliminary project. For this purpose a TOF (Time of Flight) laser scanner was used to survey the area where the runways are planned to be realized.

\subsection{Related works}

During the past years the scientific community undertook surveys to obtain detailed maps of landscapes in extreme environments.

It represents a challenging opportunity both for the personnel and instruments which are not usually manufactured to operate in such hostile places.

Many LIDAR surveys in extreme environments were usually performed exploiting airborne laser scanner, both on plane or

Figure 1. Airstrip on the sea ice shelf, Thetys Bay, Antarctica 
helicopter, which allows to acquire large amount of geometrical data over large portion of landscape.

During the austral summer of 2001-2002 airborne laser scanning data were collected in Antarctica over the summit plateau of Erebus volcano (Csatho, 2005; Csatho, 2008). The final goal was to provide a high precision map of the active craters, to evaluate the potential of the airborne laser scanning method for topographic activity in Antarctica and to establish calibration/validation standards (Mc Murdo Sound area).

This range based technique was also used to measure the elevation and surface roughness of sea ice in East Antarctica.

The Antarctic Australian Division is involved in The Sea Ice Physics and Ecosystem eXperiment II (SIPEX-II). As part of this project, a TLS (Terrestrial Laser Scanner) survey was made in combination with snow and ice depth measurements. The final DEM will contribute to a three-dimensional picture of snow and ice thickness and topography (Lieser, 2008).

An interesting scanning project (Antarctica New Zealand Event $\mathrm{K} 021$ ) in the field of cultural heritage was performed by the University of Waikato (New Zealand), together with national and international private companies, to digitize, preserve and valorise Scott's huts at Hut Point and Cape Evans, and Shackleton's hut at Cape Royds (Gibb, 2011). These prefabricated wooden huts represent some of the few heritage sites in Antarctica and thus are considered artefacts of great value.

Besides the specific goals of the project, this study was useful to provide a proof-of-concept that validate the research methodology in a complex and extreme environment.

The same kind of experiences were carried out in the arctic area. An airborne laser scanning survey was taken to monitor the ice elevation and sea-ice thickness in Greenland (Forsberg, 2001). The measurements in the polar sea north of Greenland have shown that sea-ice freeboard can readily be measured using laser sensors.

During 2012 a 16-member team, funded in part by NSF's Arctic Sciences Division, measured the snow cover of the North Slope of Alaska using a variety of techniques including terrestrial laser scanning. The goal of the project was to develop a more effective way of measuring snow depth in variable conditions and over large areas (Sturm, 2012).

\subsection{Environmental Conditions}

Summer season in the Terra Nova Bay area is characterized by h 24 sun irradiation (in absence of cloud coverage) and temperature range between $-10^{\circ} /+5^{\circ}$ Celsius. The wind-chill, which is the perceived decrease in air temperature felt by the body on exposed skin due to the flow of cold air, can be lower according with weather conditions.

The wind speed is also variable from the total absence of wind to strong wind condition up to $150 \mathrm{~km} / \mathrm{h}$. The latter goes under the name of katabatic wind formed by cold and dense air flowing out from the polar plateau of the interior down the steep vertical drops along the coast.

The area of Boulder Clay is a debris covered glacier (Figure 2). The superficial morphology of this ice-free area is characterized by lateral and shear moraine ridges, large nets and patterned grounds and, above all, by many debris cones located near frozen lakes (Gragnani, 1998; Guglielmin, 2003).

\subsection{Survey Planning}

Before the ENEA UTICT (Technical Unit for ICT) laser scanning team departure to Antarctica, the ENEA UTA staff (Technical Unit for Antarctica) provided GPS points and cartography to study the features of the portion of land which was planned to be digitized. At the beginning the target area was identified in "Antenna Camp", two km far from the Italian Research Station, which insists on granitic bed rock. However, the initial target area was changed due to environmental issues and newly identified in the Boulder Clay moraine.

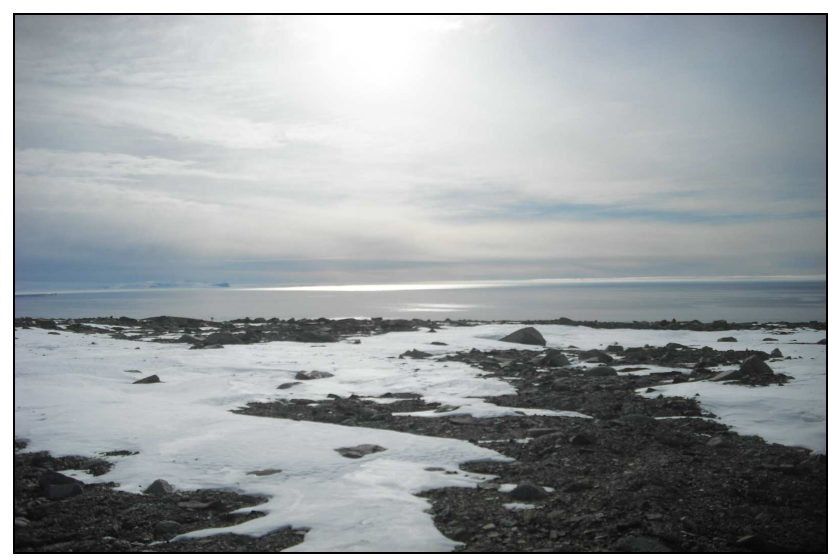

Figure 2. Boulder Clay moraine

GPS endpoints of the main airstrip's axis were provided as well (Table 1).

\begin{tabular}{|c|c|c|}
\hline $\begin{array}{c}\text { GPS } \\
\text { Points }\end{array}$ & $\begin{array}{c}\text { Southern } \\
\text { Coordinates }\end{array}$ & $\begin{array}{c}\text { Eastern } \\
\text { Coordinates }\end{array}$ \\
\hline point 1 & ${\mathrm{~S} 74^{\circ} 43.978^{\prime}}^{\prime}$ & E164 $02.924^{\prime}$ \\
\hline point 2 & ${\mathrm{~S} 74^{\circ} 45.194^{\prime}}^{\prime}$ & E164 $01.056^{\prime}$ \\
\hline
\end{tabular}

Table 1. GPS end points main runway

In order to plan the network of scanning stations, it was used the Google Earth ${ }^{\mathrm{TM}}$ software which allowed to create a visual pattern for technicians to find their way through such flat surface (Figure 3). The two GPS points where imported into the software and according to them it was possible to plan all the other laser scanning stations. For each position the latitude and longitude were extracted and imported into a GPS mobile device used on field.

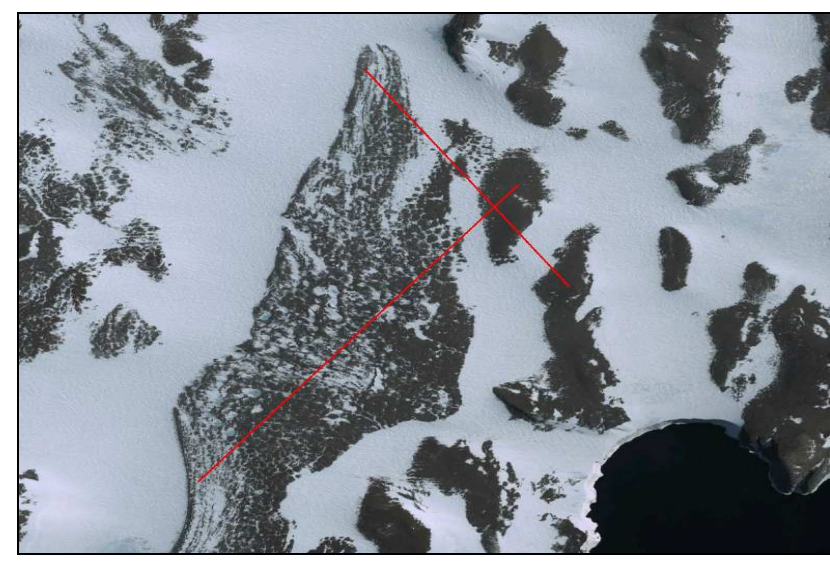

Figure 3. Boulder Clay runways main axis visualized with Google Earth ${ }^{\mathrm{TM}}$

With the help of the logistic staff of the base extendible metal supports for targets and a movable table to house the laptop during stations setup were realized. 
Tilt and Turn ${ }^{\mathrm{TM}}$ HDS targets together with spherical targets were planned to be used.

Spherical targets were realized adapting garden lamps of known diameter, which length was previously set in the laser scanner software preferences, painted in red to make them more visible in a bright and open environment.

\section{THE SURVEY}

\subsection{Field Campaign}

The priority was given to a strip of 2400 meters length for 200 meters width (100 meters each side departing from the middle axis identified by GPS coordinates) to be digitized in 40 days of fieldwork in Antarctica.

The area target of the survey presented an altitude difference of 25 meters between the lowest point and the highest point.

The personnel on the field was represented by two unit, shifted on the target area from the base each day by helicopter.

The working time run usually from 8 am to $7 \mathrm{pm}$.

The instruments on field were:

- Terrestrial Laser Scanner;

- Tripod;

- Electrical generator

- Supports for the targets and laptop;

- HDS targets and spherical targets;

- Laptop;

- Cables;

- Gasoline backup.

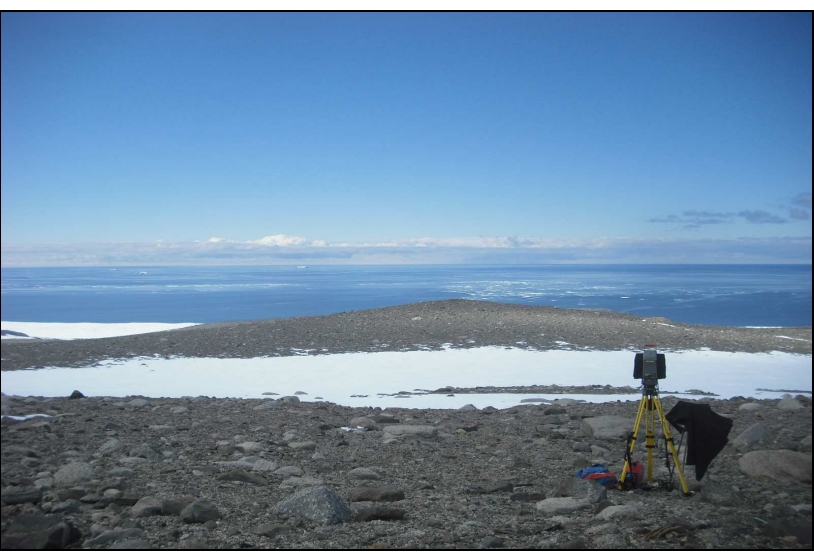

Figure 4. Scan station at Boulder Clay moraine

All equipment was recovered in a shelter placed in a visible position, which served also as recovery for surveyors in case of bad weather conditions.

Although it doesn't seems to be an impossible task to accomplish, it resulted extremely complicated and time consuming, especially during first stations, to move all the materials in an environment like Antarctica where for everyone is mandatory to wear special gears and cloths.

It was decided to place each station 70 meters far from each other with the aim to digitize an area 250 meters wide with the highest points density in the zone where the airstrip is planned to be built. In order to move targets only when necessary they were placed in the middle of an hypothetical square pattern which vertices where identified with the scan stations. However additional stations were executed where necessary.

The resolution set for each point cloud was of 10 centimetres (X axis) $x$ centimetres ( $\mathrm{Y}$ axis) with a probe at 70 meters.
The first airstrip area was digitized performing eighty-two stations in 20 days of field work (the first campaign began on December 32012 and it was completed on December 28 2012). The field of view of the laser scanner (FOV) was set from $0^{\circ}$ to $360^{\circ}$ horizontal axis and from $-45^{\circ}$ to $+5^{\circ} \%+10^{\circ}$ vertical axis. This configuration permitted to use only the front window of the scanner which is equipped also with a top window (used from $27^{\circ}$ to $90^{\circ}$ vertical axis).

At the beginning of the survey it was decided to use mixed targets, privileging the spherical targets due to visibility convenience.

The spheres acquisition failed during scanning probably caused by the long range distance between them and the laser scanner head.

The diameter of the spheres utilized was of $15.9 \mathrm{~cm}$. Nevertheless it was not possible to make use of spheres of larger dimensions since they would have been too exposed to the wind action which could have affected their position and stability.

After the first stations it was decided to proceed only with HDS targets. They were indeed easily recognizable due to their specific reflectance value and their height over the extendible supports on the ground.

Each station needed at least 40 minutes subdivided between instruments moving, station setup and scanning time (Figure 4). According with the station leader and the runways construction project manager it was decided to digitize another portion of terrain next to the moraine where it is planned to realize an emergency airstrip to use in case of headwind. Due to lack of time and to different landscape features, characterized by extensive snowfields, each scan was performed optimizing the resolution, creating dedicated software script. The same resolution $(10 \mathrm{~cm} \times 5 \mathrm{~cm})$ was maintained for areas with emerging rock outcrops. Lower resolution was set over flat snow areas. This solution allowed to shorten the scanning time, preserving the project accuracy.

The emergency runway is $1600 \mathrm{~m}$ long (Table 2). It was used the same template which provides stations each 70 meters.

\begin{tabular}{|c|c|c|}
\hline $\begin{array}{c}\text { GPS } \\
\text { Points }\end{array}$ & $\begin{array}{c}\text { Southern } \\
\text { Coordinates }\end{array}$ & $\begin{array}{c}\text { Eastern } \\
\text { Coordinates }\end{array}$ \\
\hline point 1 & ${\mathrm{~S} 74^{\circ} 44.30^{\prime}}^{\prime}$ & $\mathrm{E} 164^{\circ} 03.64^{\prime}$ \\
\hline point 2 & ${\mathrm{~S} 74^{\circ} 43.68^{\prime}}^{\prime}$ & $\mathrm{E} 164^{\circ} 01.28^{\prime}$ \\
\hline
\end{tabular}

Table 2. GPS end points headwind runway

The second survey began on 29 December 2012 and ended on 4 January 2013 when all the equipment was shifted back to the base. Fifty stations were performed to acquire the portion of land for the headwind airstrip (Table 3).

\begin{tabular}{|c|c|c|}
\hline & Main Airstrip & Headwind Airstrip \\
\hline Scan Stations & 82 & 50 \\
\hline Resolution & $10 \mathrm{~cm} \times 5 \mathrm{~cm}$ & $10 \mathrm{~cm} \mathrm{x} \sim \mathrm{cm}$ \\
\hline Probe & $70 \mathrm{~m}$ & $\sim 70 \mathrm{~m}$ \\
\hline Targets & 103 & 100 \\
\hline Survey Time & 20 days & 6 days \\
\hline
\end{tabular}

Table 3. Survey data

Five of the targets acquired with the laser scanner during the campaign were also acquired by differential GPS (DGPS) by the staff of the University of Bologna in order to geo-reference the global point cloud in a known reference system. 
Tilt and Turn targets ${ }^{\mathrm{TM}}$ were placed over permanent metal bars on ground which will be used in the future to monitor the moraine's spatial movement.

\subsection{Environmental Problems}

There were concerns before the campaign about some issues related to the temperature and the snow coverage of the landscape which could affect the laser scanner data.

Firstly not all scanner operate below $0^{\circ} \mathrm{C}$, which is the lowest temperature certified by the manufacturer for the laser scanner employed. TOF laser scanners in particular struggle due the inability of the laser pump to operate in below zero temperatures.

To avoid malfunctions, two covers were realized in black tissue with the dual purpose of:

- heat the device through the capture of solar radiation;

- obstruct cooling vents to maintain the internal temperature higher.

Another issue was related to the digitization of snow and ice. The laser beam acquired data over the snow while showed lack of data over solid ice where it was absorbed by the surfaces (frozen lakes).

For the duration of the laser scanning campaign the ENEA team had to face different kind of problems due to particular environmental conditions.

First of all the low temperatures, especially during windy days, made the operations particularly difficult.

This condition affects in particular the battery life (scanner and laptop) which is significantly reduced while recharge times are extended. These causes mainly led to use an electrical generator as power source.

The wind itself was a problem since it made difficult the laser scanner setup. As well-known the scanner requires a stable platform, at least for the duration of each scan. When too strong, the tripod could tremble and also the initialization process of the instrument could sometime fail.

The tripod was hence stabilized and anchored to the ground with heavy stones.

Another issue related to the wind was the transport of the sand which can impair such specialized digital equipment containing sensitive optics. However this effect didn't result in any visible wrong data or problem for the 3D scanner.

The high sun irradiation prevent the user to visualize the data acquired in real time due to reflection on the screen laptop. The surveyor during scan station setup, target acquisition and final check was obliged to cover himself and laptop with a black sheet to have a proper visualization environment.

Another problem was identified while scan positions were performed over the snow. It has been noticed that although the tripod was properly fixed on the ground, after some time, the bubble level came outside range. It was caused by the tripod which melted the snow around the tips of its legs and then make plunging itself.

The snow represented another concern since it was acquired during light snow storm by the scanner even if each snowflake was supposed to be under the minimum size detectable.

\section{DATA ANALYSIS}

\subsection{Point Cloud Post Processing}

The two runways (the first one composed by 82 stations and the second one by 50 stations) were aligned in the same reference system using the software Cyclone ${ }^{\mathrm{TM}}$. The final point cloud consisted of 600 million points (Figure 5).

Two hundred and three HDS targets together with cloud constraints were used for the registration. However the ICP algorithm didn't refine the registration significantly due to missing overlapping area in a such flat and occluded surface. For some scan pairs it was necessary to provide manual reference points to achieve a reliable registration. The final RMS error was in the order of $10 \mathrm{~cm}$ which is negligible according with the final goal of the project.

The point cloud was filtered to eliminate:

- noise represented by the snow (identifiable in few scan position);

- metal bars used as support for the HDS targets;

- personnel which were operating in the area at the same time.

The final point cloud was then decimated to attain an average space between points not lower than $5 \mathrm{~cm}$ in the main target area.

3D scanning data was geo-referenced using GPS points converted in UTM-WGS84 coordinates system. During conversion it was also applied the undulation of the geoid to get the elevation referred to the sea level.

The GPS points identified on the point cloud were labeled during the 3D survey according with a nomenclature chosen in agreement with the GPS team.

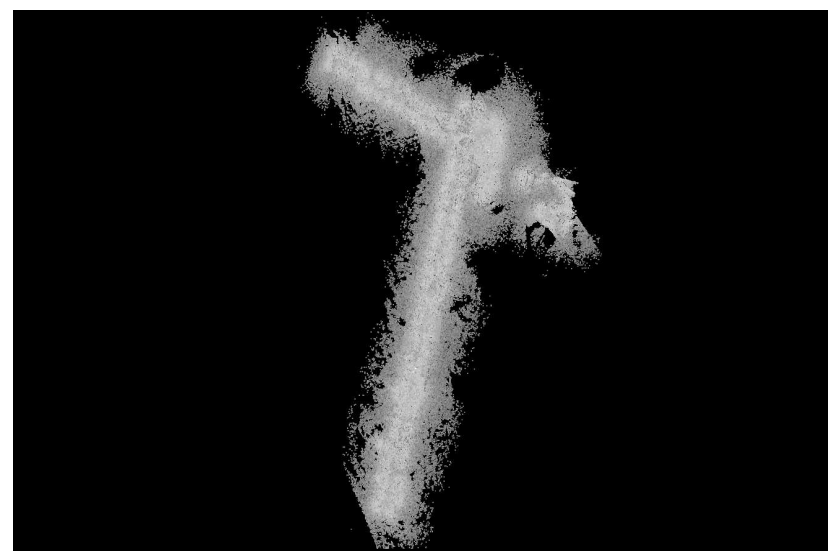

Figure 5. Final point cloud after alignment (grey scale)

During the registration an external .txt file with the UTMWGS84 GPS coordinates, labeled in the same way as in the 3D data, was imported into the software and used as reference "scan world" for the point cloud which was roto-translated on it (Table 4).

\begin{tabular}{|c|c|c|c|}
\hline ID & $\mathbf{X}$ & $\mathbf{Y}$ & El \\
\hline georef1 & 471943.630248597 & 1705772.54164684 & 201.2214 \\
\hline georef2 & 471850.492247428 & 1705427.60027651 & 196.7199 \\
\hline georef3 & 471421.478591213 & 1704312.39731468 & 201.0718 \\
\hline georef4 & 471364.353079218 & 1704229.23133872 & 203.7876 \\
\hline georef5 & 471302.135397132 & 1706447.82229088 & 215.7203 \\
\hline
\end{tabular}

Table 4. DGPS UTM-WGS84 GPS coordinates

After the geo referencing process the average error among the five control points was $\sim 5 \mathrm{~cm}$. 


\subsection{Data Extraction}

After the creation of the triangulated Irregular Network (TIN), contour lines in a range of $50 \mathrm{~cm}$ from each other were extracted and subsequently superimposed on a low resolution photogrammetric Digital Elevation Model (Figure 6).

Due to high resolution of the point cloud and the tight steps between contour lines, also small rocks and outcrops were drawn. These vectors were then identified and removed manually to get a "clean" model.

However all undesired data were assigned on a specific layer with the possibility to retrieve them if necessary.

The global vector file contained also contour lines resulting from areas interpolated arbitrarily by the software.

These areas, which were then unreal, misleading and not reliable for the development of the runways project, were removed. In order to achieve this goal the ideal pattern of the runways was outlined in a single dxf file according with the main axis of the airstrips. For this purpose it was only considered the area where the point density of $5 \mathrm{~cm}$ was certain and reliable ( 120 meters on each side of the ideal axis).

The resulting file allowed to crop, manipulate and process the initials contour lines exploiting the software Surfer ${ }^{\mathrm{TM}}$.

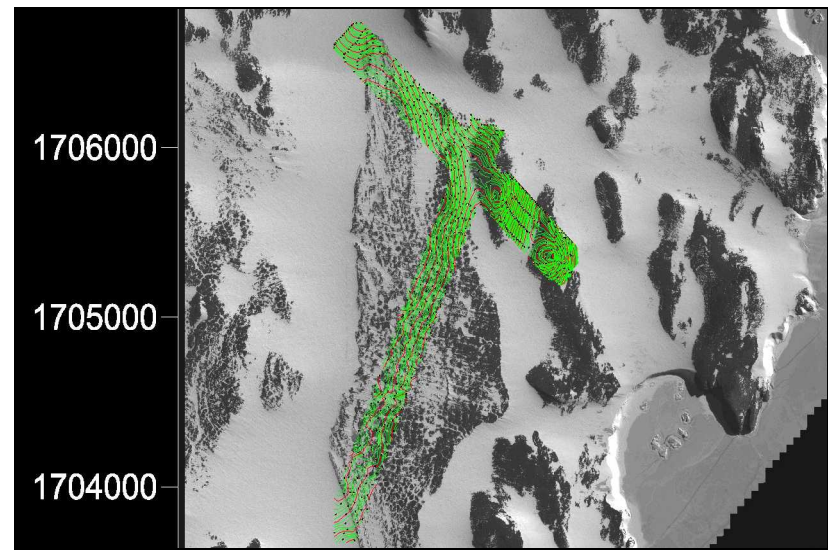

Figure 6. Contour lines superimposed on satellite image

It was also possible to extract detailed profiles along the main axis of the two runways to study the best alignment of the airstrips on the terrain according with the surrounding areas.

Several reference planes have been created and then positioned in accordance with the UCS (User Coordinate System) specifically relocated runway's axis. Successively the cutting planes were executed by moving the reference plane with a 1 meter offset.

During the preliminary studies of the main runway position, it has been decided to avoid the lake-ice blisters which characterize the moraine morphology. These elements will be indeed analyzed at further stages with geophysical techniques to find out the presence of hyper concentrated saline solutions (Guglielmin 2009).

The proposed runway configuration is mainly horizontal according with the moraine expansion (Figure 7).

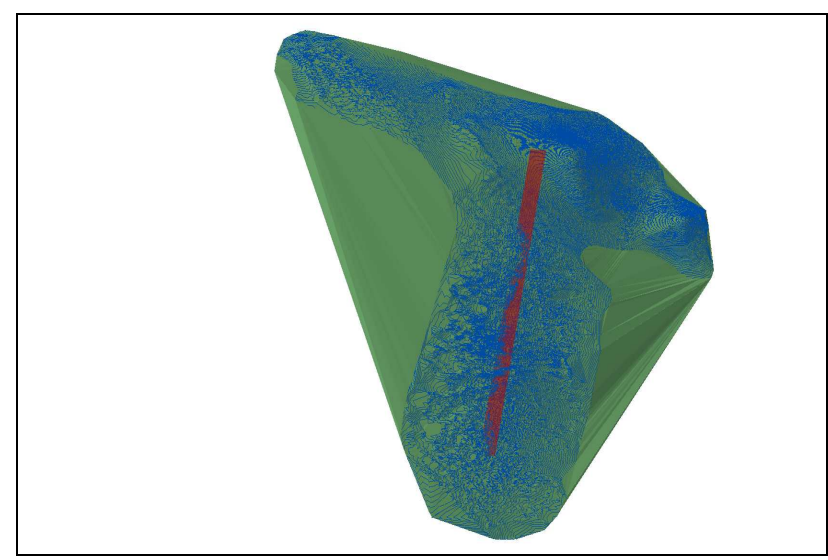

Figure 7. Main runway hypothetical position

The elevation, referred to the sea level, is 205 meters North and 204 meters South with an airstrip length of 1800 meters and width of 60 meters.

The laser scanner data have been consequently used for volume analysis with the purpose of both calculating the amount of terrain to move and to assess the structure's cost of construction in terms of personnel, equipment and time needed (Figure 9). The tool used for this purposed has been ArcGIS 3D Analyst ${ }^{\mathrm{TM}}$.

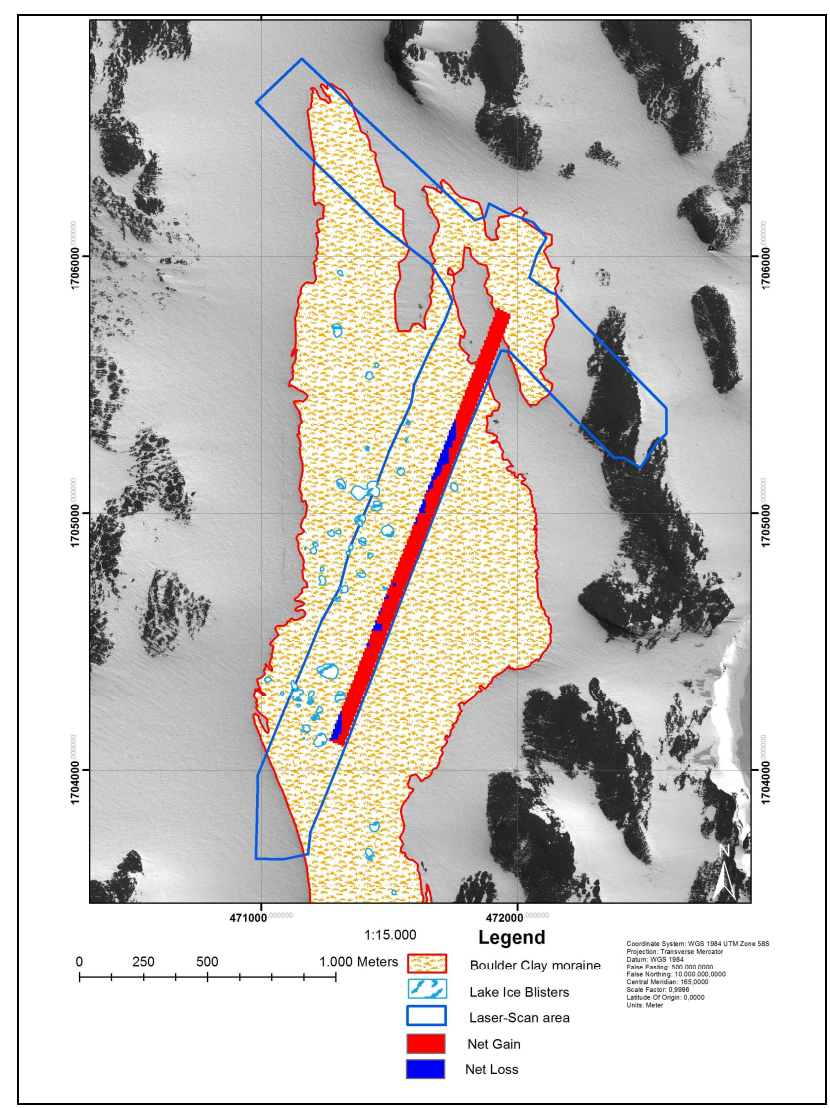

Figure 9. Main runway volume analysis 
The Net Gain (red color) represents the area where it will be necessary to move soil. The Net Loss (blue color) is the area where it will be removed soil.

\begin{tabular}{|c|c|c|}
\hline & Volume $\left(\mathrm{m}^{3}\right)$ & Area $\left(\mathrm{m}^{2}\right)$ \\
\hline Net Gain & $-265315,564328$ & 95287,208619 \\
\hline Net Loss & 8149,980616 & 12808,177228 \\
\hline
\end{tabular}

Table 5. Volume $\left(\mathrm{m}^{3}\right)$

\section{CONCLUSIONS}

Under the patronage of the Italian National Research Programme in Antarctica (PNRA), in this paper it has been described the use of TLS scanning in an extreme environment, with the final goal to produce contour lines with $50 \mathrm{~cm}$ of equidistance for runway project development.

Although the pipeline needed to obtain contour lines from Digital Elevation Model is a well-known and established process over the scientific community, in this study the main aim was to present:

- the methodological and environmental challenges faced when surveying in harsh conditions;

- the technological issues arose during field campaign in Antarctica.

The solutions adopted for the preparation and the execution of the field survey were presented together with the final and still on-going results (contour lines creation, runway positioning and volume calculation) achieved after the elaboration of the laser scanner data.

From a methodological point of view future developments are represented by the standardization of some procedures on field with the aim to improve the 3D data acquisition workflow and reduce errors during the registration and geo-referencing process.

\section{ACKNOWLEDGEMENTS}

The ENEA UTICT laser scanning team would like to thank the Italian National Research Programme in Antarctica (PNRA) and the personnel of the Italian Research Station in Antarctica "Mario Zucchelli" of the XXVIII ${ }^{\circ}$ scientific campaign, II period, for the support given during the field survey operations. We are also thankful with Prof. A, Zanutta and Prof. L. Vittuari of the University of Bologna, DICAM Department, for the DGPS data acquisition and analysis.

\section{REFERENCES}

Bromwich D. H., Kurtz D. D., 2012 Katabatic wind forcing of the Terra Nova Bay polynya, Journal of Geophysical Research: Oceans, Vol 89 Issue C3,

http://onlinelibrary.wiley.com/doi/10.1029/JC089iC03p03561/a bstract

Csatho B., Schenk T., Kyle P., Wilson T., Krabill W.B., Lyons W., McKenzie G., Hallam C., Manizade S., Paulsen T., 2005, Airborne Laser Scanning for High-Resolution Mapping of Antarctica, Eos, Vol.86 No. 25, pp. 237-239

Csatho B., Schenk T., Kyle P., Wilson T., Krabill W.B., 2008, Airborne laser swath mapping of the summit of Erebus volcano, Antarctica: Applications to geological mapping of a volcano,
Journal of Volcanology and Geothermal Research, Volume 177, Issue 3, pp. 531-548

Forsberg R., Keller K., Jacobsen S.M., 2001, Laser monitoring of ice elevations and sea-ice thickness in Geenland, The In: International Archives of the Photogrammetry, Remote Sensing and Spatial Information Sciences, Volume XXXIV-3/W4 Annapolis, MD, 22-24 Oct. 2001, pp. 163-168

Gibb R. , McCurdy D., Farrell R., Bathow C., Breuckmann B., 2011, Use of multi-resolution laser scanning/white light scanning and digital modelling of the historic huts of scott and shackleton in antarctica, Journal Geoinformatics FCE CTU, Volume 7

Gragnani R., Guglielmin M., Longinelli A., Stenni B., Smiraglia C., Cimino L., 1998, Permafrost, Proceedings of the Seventh International Conference, Collection Nordicana No 55, pp. 335-340

Guglielmin M., Balks M., Paetzold R., 2003, Towards an Antarctic active layer and permafrost monitoring network, Permafrost, pp. 337-341

Guglielmin M., Lewkowicz A., French H.M., Strini A., LakeIce blisters, Terra Nova bay area, northern Victoria land, Antarctica, 2009, Geografiska Annaler, 91 A (2), pp. 99-111

Lieser J.L., Determining sea ice thickness with an airborne scanning laser, 2008, Antarctic Magazine, Australian Antarctic Division, Kingston, Tasmania, 14, online, pp. 16-17

Programma Nazionale di Ricerche in Antartide (PNRA), 2005, Rapporto Periodico di Attività, http://www.italiantartide.it/spedizioni/xxi/rapporti/XXI_1rappor to.pdf.

Programma Nazionale di Ricerche in Antartide (PNRA), 2008, Rapporto Periodico di Attività, http://www.italiantartide.it/spedizioni/xxiv/documentazione/Ra pporti/XXIV_1_rapporto.pdf.

Programma Nazionale di Ricerche in Antartide (PNRA), 2009, Rapporto Periodico di Attività, http://www.italiantartide.it/spedizioni/xxv/documentazione/Rap porti/1_rapporto/XXV_1_rapporto.pdf

Programma Nazionale di Ricerche in Antartide (PNRA), 2010, Rapporto Periodico di Attività, http://www.italiantartide.it/spedizioni/xxvi/documentazione/Ra pporto $\% 20$ mensile $\% 20$ n.1.pdf

Sturm M., Snowstar-2012: big "N" - the pursuit of snow data and high honor, 2012,

http://blogs.scientificamerican.com/expeditions/2012/04/22/sno wstar-2012-big-n-the-pursuit-of-snow-data-and-high-honor/ 